\title{
ANÁLISE DOS PETROTRAMAS DE EIXOS-C DE QUARTZO: ZONA DE CISALHAMENTO MAJOR GERCINO (SC)
}

\author{
C.R.Passarelli ${ }^{1} \&$ M.A.S.Basei ${ }^{2}$
}

PALAVRAS-CHAVE: zona de cisalhamento, eixo-c de quartzo, rochas miloniticas.

PASSARELLI, C.R.; BASEI, M.A.S. (1995) Análise dos petrotramas de eixos-C de quartzo: Zona de

Cisalhamento Major Gercino (SC). Bol.IG-USP, Sér.Cient., 26:99-113.

\section{RESUMO}

Este trabalho visa apresentar as principais conclusōes obtidas da utilização de petrotramas de eixos-c de quartzo, aplicadas ao estudo da Zona de Cisalhamento Major Gercino (ZCMG), no trecho Canelinha - Garcia, regiāo centro-leste do Estado de Santa Catarina.

Este lineamento faz parte do importante sistema de cisalhamento de direção NE-SW que afeta a região sul-brasileira e uruguaia. Ao longo de toda sua extensão, a ZCMG separa duas áreas geologicamente diferentes que correspondem, em Santa Catarina, aos dominios interno (granitóides) e intermediário (supracrustais) do Cinturăo Dom Feliciano (CDF). Esta zona de cisalhamento possui estruturaçäo geral $\mathrm{NE}$, caracteristicas dúcteis-rúpteis e movimentação predominantemente dextral. A geração das rochas miloniticas deu-se, principalmente, no grau metamórfico xisto-verde.

$\mathrm{Na}$ região estudada, a ZCMG caracteriza-se por duas faixas miloniticas onde predominam rochas com texturas protomiloniticas e miloniticas. Entre essas faixas ocorre um conjunto de granitóides associado ao desenvolvimento da ZCMG. A faixa milonítica norte limita os metassedimentos do Grupo Brusque a noroeste dos granitóides centrais e a faixa milonítica sul faz o contato entre esses granitóides e as rochas do Complexo-Granito-Migmatítico (Domínio Interno do CDF).

A componente coaxial é sugerida nos petrotramas de eixos-c de quartzo por concentraçôes simétricas em relaçầo à foliação milonítica, bem como pela existência de porfiroclastos simétricos em seçŏes delgadas. A componente da deformação por cisalhamento puro pode ter acarretado, em inflexōes locais, movimentaçōes sinistrais.

As rochas miloníticas da ZCMG apresentam orientaçầo cristalográfica desenvolvida sob temperaturas relativamente baixas, indicada pelo metamorfismo no fácies xisto-verde e pelos petrotramas. Apesar da baixa temperatura, o processo de cisalhamento ocorreu em condiçōes de alta taxa de deformaçâo, evidenciada pela presença de minerais deformados e estirados e pela geração de rochas miloniticas e ultramiloníticas, onde comumente ocorre total paralelizaçăo das superficies $\mathrm{S}$ e $\mathrm{C}$.

\section{ABSTRACT}

The analysis of quartz c-axis improved the kinematic characterization of the Major Gercino Shear Zone (MGSZ) in the Canelinha - Garcia area in central-eastern Santa Catarina State. This shear zone is one of the major lineaments that affect all southern Brazilian and Uruguaian precambrian terrains. In Santa Catarina the MGSZ separates supracrustal rocks of the Brusque Group (northern part)

\footnotetext{
${ }^{1}$ Aluna Pós-Graduanda, IG/USP.

'Departamento de Geologia Geral, Instituto de Geociências/USP, Săo Paulo, Brasil.
} 
from the Granitoid-Migmatitic Complex to the south. This zone is characterized by a regional NE trend, a dextral sense of movement, and predominantly ductile-brittle structures.

The MGSZ is composed of two mylonitic belts to the northwest and southeast, respectively, separated by granitoid rocks probably associated with the development of the shear zone. Both shear zones have cataclastic to ultramylonitc rocks, but mylonites and protomylonites predominate. Most of the mylonitic rocks were produced under greenschist facies metamorphic conditions and a high strain rate.

Although sinistral displacement is often observed, most of the mesoscopic structures and kinematic indicators show a predominance of dextral movement with an important oblique component. The results of c-axis analyses in quartz-rich rocks are in good agreement with this interpretation and also indicate a coaxial deformation produced by pure shear strain as can be seen in the symmetric pattern of the prefered orientations of the c-axis in many of the diagrams obtained in the MGSZ, as well as indicated by the presence of local sinistral shear movements.

The mylonitic rocks of the MGSZ have crystallographic orientations developed at relatively low temperatures, as confirmed by the low-grade metamorphic conditions. In spite of the low temperatures, the orientation developed under a high strain rate as shown by the deformed and stretched minerals and the commom parallelism of $\mathrm{S}$ and $\mathrm{C}$ surfaces.

\section{INTRODUÇÃO}

Pretende-se neste trabalho abordar aspectos relacionados aos petrotramas de eixos-c de quartzo, que se constituem em uma ferramenta importante nos estudos estruturais, bem como discutir os resultados de sua aplicação à Zona de Cisalhamento Major Gercino (ZCMG), em Santa Catarina.

Quando uma rocha é deformada, comumente ela desenvolve uma orientação preferencial das direções cristalográficas dos minerais que a constituem. Normalmente representa-se o padrão da orientação preferencial de uma direção cristalográfica particular. O estudo das orientações cristalográficas preferenciais é de grande interesse para a geologia estrutural pois o petrotrama desenvolvido é relacionado: 1) aos mecanismos da deformação; 2) com a forma do elipsóide de deformação finita (oblato, prolato, deformação plana) e 3) com o padrão da deformação ou arcabouço cinemático (Schmid \& Casey, 1986).

A Zona de Cisalhamento Major Gercino faz parte do importante sistema de cisalhamento, com direção NE-SW, que afeta a porção pré-cambriana da regiāo sul brasileira e uruguaia. $O$ segmento estudado situa-se na regiāo cen- tro-este do estado de Santa Catarina, abrangendo os municípios de São João Batista, Canelinha, Tijipió, Major Gercino e Garcia. Ao longo de toda sua extensão a ZCMG separa duas áreas geologicamente diferentes que correspondem, em Santa Catarina, aos domínios interno (granitóides) e intermediário (supracrustais) do Cinturão Dom Feliciano (CDF), como definidos por Basei (1985) (Fig. 1).

\section{METODOLOGLA}

Para o estudo dos petrotramas de rochas miloníticas torna-se necessário a utilização de lâminas delgadas orientadas. As medições de eixos-c de quartzo são realizadas em platina universal, em cortes XZ do elipsóide de deformação de amostras orientadas.

Neste item serão abordados os procedimentos relacionados à coleta de amostras orientadas e a medição de eixos-c de quartzo em platina universal de 4 eixos.

\section{Coleta de amostras orientadas}

A coleta de amostras orientadas é realizada, preferencialmente, em aflo- 


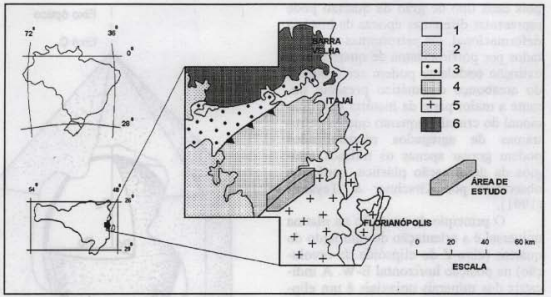

Figura 1 - Localização da área no CDF (conforme Basei, 1985). 1) Depósitos Cenozóicos; 2) Sedimentos Paleozóicos; 3) Domínio Externo: Grupo Itajai; 4) Domínio Intermediário: Grupo Brusque e Granitóides intrusivos; 5) Domínio Interno: Granitóides deformados, gnaisses migmatíticos e granitóides intrusivos; 6) Ortogranulitos da Microplaca Luis Alves.

ramentos com foliação milonítica e lineação de estiramento bem evidenciadas, com o seguinte procedimento:

1) Anotação da atitude do plano orientado, marcando-se a horizontal do plano na amostra com uma seta indicativa do rumo da direção. Faz-se a anotação de sinal positivo $(+)$ se o plano orientado apresenta face voltada para cima ou, sinal negativo (-) se o plano possui face voltada para baixo. De preferência, orienta-se um plano positivo para maior facilidade de manuseio posterior.

2) Confecçăo de cortes $X Z$ (normal à foliação milonítica e paralelo à lineação de estiramento) e posterior determinação de sua direção. Orienta-se o corte do mesmo modo com que se marcou o plano orientado no campo. A lâmina deve apresentar a foliação orientada N-S ou E-W. Constitui o último passo desta etapa a certificação de que as lâminas delgadas foram confeccionadas com as lamínulas coladas nas faces positivas desses planos.

\section{Medição dos eixos-c de quartzo}

As mediçōes de eixos-c de quartzo são realizadas nas faces positivas dos cortes XZ. Apesar de não ser relevante a direção deste plano, é de grande importância a relação da foliação milonítica com as concentrações dos eixos medidos.

A medição dos eixos-c de quartzo pode ser efetuada em Platina Universal de 4 ou 5 eixos. No presente trabalho foram medidos de 100 a 200 eixos-c, com uma média de 160 eixos por amostra, nos cortes XZ de rochas miloníticas e protomiloníticas graniticas em Platina Universal de 4 eixos.

Antes de iniciar a medição é interessante a verificação da existência ou não de uma orientação preferencial com o auxílio da placa de gipso. Posteriormente, caracterizam-se as populaçōes de quartzo existentes na amostra (recristalizados, serrilhados, recuperados ou com extinção ondulante). As medições de cada populaçẩo devem ser diferenciadas, 
pois cada tipo de grão de quartzo pode representar diferentes épocas da história deformacional. Os petrotramas apresentados por porfiroclastos de quartzo com extinção ondulante podem ser produtos do arcabouço cinemático presente durante a maior parte da história deformacional do cristal, enquanto que os petrotramas de agregados recristalizados podem gravar apenas os últimos estágios da deformação plástica, conforme observado por Kirschner \& Teyssier (1991).

O princípio de medição na platina universal é a orientação do raio lento do quartzo (eixo- $Z$ do elipsóide de revolução) na posição horizontal E-W. A indicatriz dos minerais uniaxiais é um elipsóide de revolução, cujo eixo coincide com o eixo óptico e, portanto, paralelo ao eixo cristalográfico c do mineral (Fig. 2).

Antes do início das medidas devese centralizar a platina exterior com as objetivas que serão utilizadas (que dependerāo da granulometria da amostra), e em seguida centralizar o eixo vertical interno com a platina fixa, com auxilio dos parafusos internos. Inicia-se a mediçâo, obedecendo-se ao seguinte procedimento:

-posicionar todos os eixos da platina $\mathrm{cm} 0^{\circ}$;

-selecionar o grão e, com nicóis cruzados, iniciar a identificaçâo do raio lento $(\mathrm{Z})$;

-extinguir o grão de quartzo por meio do eixo vertical interno da platina; - girar $45^{\circ}$ da posição de extinção: nesta posição o mineral se apresenta na máxima luminosidade portanto, as duas direções de vibração do mineral são paralelas às vibraçóes do raio lento e rápido do acessório, quando introduzido no microscópio;

-introduzir a placa de gipso (raio rápido paralelo ao maior comprimento do acessório): se houver adição nas cores de interferência, significa que a dire-

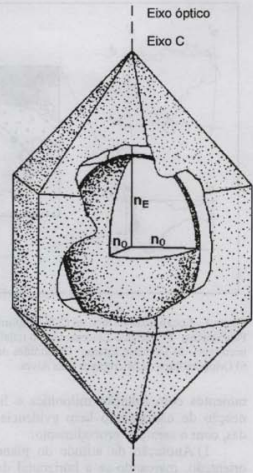

Figura 2 - Cristal uniaxial positivo (quartzo) mostrando a indicatriz.

ção do raio lento do mineral é paralela à direção do raio lento do acessório, então gira-se a platina $45^{\circ}$ no sentido horário; se houver subtração nas cores de interferência, a direção do raio lento do mineral é paralela à direção do raio rápido do acessório, então gira-se a platina $45^{\circ}$ no sentido anti-horário.

Esta primeira etapa pode ser realizada de modo mais simples, sem o auxilio da placa de gipso:

-extinguir o grão;

- quebrar a extinção com o eixo EW; se quebrar totalmente, 0 grão já está na posição correta para o próximo passo; se não quebrar a extinção, ou quebrar muito pouco, movimenta-se o 
grâo para outra posição de extinção.

Neste estágio o eixo-c do quartzo, ou raio lento, está na posição $\mathrm{E}-\mathrm{W}$ da platina.

-girar o eixo $\mathrm{E}-\mathrm{W}$ : houve quebra na extinção;

-reestabelecer a extinção no eixo

$\mathrm{N}-\mathrm{S}$, com o menor ângulo possível;

-testar novamente o eixo E-W; o grāo deve permanecer extinto;

- colocar o eixo E-W na posição horizontal $0^{\circ}$;

-girar $45^{\circ}$ a platina exterior: se a seção se iluminar então o eixo- $Z$ está paralelo a E-W, e a medida já está correta (ex: $240,50 \mathrm{D})$; se a seção se extingue, então o eixo- $Z$ está perpendicular a $\mathrm{E}-\mathrm{W}$ e anota-se $\mathrm{o}$ ângulo complementar daquele observado, mudando-se o caimento do mesmo (ex: 240,40 E).

É muito importante anotar-se o tipo de grão de quartzo medido e dife- renciar as medidas caso se meça diferentes populaçōes de grãos.

As medições obtidas podem ser tratadas $\mathrm{cm}$ microcomputadores em programa Stereonet.

\section{ASPECTOS GERAIS DA ZONA DE CISALHAMENTO MAJOR GERCI- NO}

Na região estudada, a ZCMG caracteriza-se por uma faixa milonitica principal a noroeste (FMN), com largura variável entre 1 e $3.75 \mathrm{~km}$, apresentando desde cataclasitos até ultramilonitos, predominando rochas com texturas protomiloníticas e miloníticas, e uma faixa milonítica sudeste (FMS), com largura entre $500 \mathrm{~m}$ e $2 \mathrm{~km}$, onde ocorrem milonitos e ultramilonitos. Entre essas faixas ocorre um conjunto de granitóides (Fig. 3).

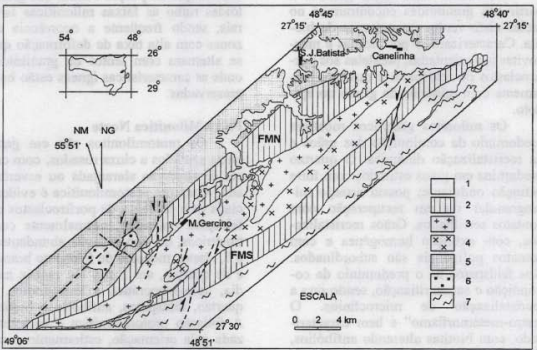

Figura 3 - Esboço geológico da Zona de Cisalhamento Major Gercino (SC). 1) Aluviões continentais. ZCMG: 2) Faixa Milonítica Norte (FMN) e Faixa Milonítica Sul (FMS); 3) Associação Granitóide Fernandes; 4) Associação Granitóide Rolador. Terrenes a norte da ZCMG: 5) Grupo Brusque; 6) Granitóides intrusivos. Terrenos a sul da ZCMG: 7) Complexo Granito-Migmatítico. 
A faixa milonitica norte limita os metassedimentos do Grupo Brusque (mica-quartzo xistos, filitos e subordinadamente quartzitos) a noroeste dos granitóides centrais. A faixa milonítica sul faz o contato entre esses mesmos granitóides e os granitóides do Complexo Granito-Migmatítico (Dominio Interno do $\mathrm{CDF}$ ).

Os granitóides centrais, normalmente pouco deformados, foram subdivididos em duas associaçōes principais. $\mathrm{Na}$ primeira, Associação Granitóide Fernandes, predomina uma série petrográfica de sienogranitos róseos, grossos, porfiróides, a anfibólio e, na segunda, Associação Granitóide Rolador, monzogranitos porfiríticos a porfiróides, conforme definidos por Passarelli (1996). Os corpos graníticos centrais mostram-se normalmente isótropos, porém podem apresentar-se foliados, miloníticos ou com feições cataclásticas.

As rochas miloníticas geradas a partir dos granitóides encontram-se no fácies xisto-verde, em presença de biotita. Caracterizam-se por biotitas e muscovitas iso-orientadas, paralelas aos porfiroclastos de feldspatos e quartzo, juntamente com minerais do grupo do epidoto.

Os milonitos graníticos mostram predomínio da cominuiçâo dos grăos e da recristalização dinâmica. $\mathbf{O}$ quartzo predomina em grãos estirados com forte extinção ondulante; possui arranjo microgranular ou em recuperação com contatos serrilhados. Grãos recristalizados, com extinçâo homogênea e com contatos poligonais são subordinados. Nos feldspatos há o predomínio da cominuição e saussuritização, sendo rara a recristalizaçđ̃o de microclínios. O "retro-metamorfismo" é bem caracterizado, com biotitas alterando anfibólios, cloritas alterando biotitas e muscovitas; além de forte epidotização.

Nos miloniticos dos metassedimentos do Grupo Brusque, o metamor- fismo da ZCMG encontra-se no fäcies xisto-verde, zona da biotita, gradando localmente à zona da clorita. Os filitos miloníticos são compostos principalmente por sericita e quartzo, estando este bastante estirado com extinção ondulante, ocorrendo também grãos recuperados ou microgranulares com contatos serrilhados. A foliação milonítica é caracterizada pelos grãos de quartzo estirados e sigmoidais e pela orientação das sericitas.

O contato dos milonitos do Grupo Brusque com os milonitos graníticos se faz através de imbricamento tectônico de ambos. Podem ser observadas faixas de metassedimentos miloníticos mescladas com bandas de protomilonitos e milonitos graníticos.

A passagem entre os granitóides centrais da ZCMG e as faixas miloniticas dá-se de modo bastante heterogêneo. De modo geral ocorre um incremento da deformação da porção central dos granitóides rumo às faixas miloniticas laterais, sendo freqüente a ocorrência de zonas com alta taxa de deformação que se alternam com lentes de granitóides onde as caracteristicas igneas estão bem preservadas.

\section{Faixa Milonítica Norte}

Os protomilonitos são em geral cinza azulados a cinza rosados, com cores de alteração alaranjada ou esverdeada. A textura protomilonítica é evidenciada pela presença de porfiroclastos de feldspato potássico, normalmente centimétricos, do tipo $\sigma$ (mais abundantes) e $\delta$, clastos menores de feldspato branco e de quartzo, até $1 \mathrm{~cm}$, em matriz média, hololeucocrática a leucocrática, a quartzo, feldspatos, anfibólio e biotita. A foliaçăo protomilonítica é caracterizada pela orientação, estiramento e rotação dos minerais, observando-se também desenvolvimento de sericitas.

Estes protomilonitos podem passar gradualmente para milonitos, onde 
há menor quantidade de porfiroclastos, sendo estes mais estirados; ou podem intercalar faixas miloníticas bem delimitadas de até $50 \mathrm{~cm}$.

Os milonitos apresentam cor cinza, granulação fina, com porfiroclastos de 2 a $3 \mathrm{~mm}$, esparsos e bastante estirados, de feldspato potássico e plagioclásio (menores). $\mathrm{O}$ quartzo apresentase como porfiroclasto tipo $\sigma$, ou como filmes. A foliação milonítica caracteriza-se por planos que contém os minerais estirados, sendo comum a presença de faixas ricas em sericitas. Normalmente intercalam-se ou passam gradualmente para ultramilonitos e filonitos, de cor cinza esverdeada e aspecto xistoso, sendo rara a ocorrência de porfiroclastos de feldspato potássico.

Os milonitos do Grupo Brusque apresentam cor de alteração variegada, predominando a cor vinho nos termos mais pelíticos e cor esbranquiçada nos mais psamíticos. Distinguem-se estes milonitos dos metassedimentos não milonitizados por apresentarem, normalmente, apenas uma foliação bem marcada, caracterizada pela orientação de sericitas e cloritas.

\section{Faixa Milonítica Sul}

Os protomilonitos apresentam cor cinza, com porfiroclastos de feldspato potássico, normalmente tipo $\sigma$, de até 2 $\mathrm{cm}$, e menores de quartzo. A matriz é média, hololeucocrática a leucocrática, composta por quartzo, feldspatos e máficos, podendo apresentar quartzo azulado como filmes e feldspatos bastante estirados, por vezes com sulfetos disseminados. Os protomilonitos podem gradar para milonitos ou apresentar faixas miloníticas métricas (até $5 \mathrm{~m}$ ).

Os milonitos a ultramilonitos apresentam cor cinza escuro, cor de alteração esbranquiçada, granulação fina a muito fina, com porfiroclastos milimétricos de feldspato potássico estirados e rotacionados, em matriz leucocrática com biotitas. Na foliação milonitica são observadas muscovitas neoformadas.

\section{ANÁLISE DOS PETROTRAMAS DE EIXOS-C DE QUARTZO NA ZCMG}

\section{Introdução}

O petrotrama desenvolvido é governado por mecanismos da deformação e pelo padrão da deformação ou arcabouço cinemático (Schmid \& Casey, 1986). Então o estudo do petrotrama cristalográfico do quartzo oferece informaçōes importantes relacionadas aos estágios da deformação finita, padrão da deformação (coaxial ou não-coaxial) e sentido do cisalhamento. Ademais, permite a inferência do sistema operante de deslizamento e conseqüentemente, da temperatura operante, bem como da importância da presença de fluidos durante a deformação.

Estudos documentam a boa correlação entre os petrotramas cristalográfi$\cos$ e os estados da deformação finita (Price, 1985; Schmid \& Casey, 1986).

O petrotrama de diferentes populações de quartzo pode esclarecer parte da história deformacional. Os petrotramas de porfiroclastos podem ser produtos do arcabouço cinemático presente durante a maior parte da história da deformação plástica do cristal. Por outro lado, os petrotramas de agregados recristalizados devem gravar apenas os últimos estágios da deformação plástica (Kirschner \& Teyssier, 1991).

A mudança de temperatura durante a história deformacional pode provocar o aparecimento de diferentes petrotramas: sob temperaturas mais baixas o deslizamento basal (a) é mais fácil de ser ativado e sob temperaturas mais altas o deslizamento prismático (a) se torna predominante (Tullis et al., 1973; Kirschner \& Teyssier, 1991). A alta concentração de fluidos é outro fator que pode favorecer o deslizamento pris- 
mático enquanto a baixa concentração de fluidos o deslizamento basal (Kirschner \& Teyssier, 1991).

Sob altas taxas de deformação o petrotrama de eixo-c é orientado quase que perpendicularmente ao eixo principal de estiramento $(\mathrm{X})$. Conseqüentemente, o plano de deslizamento do cristal deve ser paralelo ao plano do cisalhamento (Lloyd et al., 1992).

Neste trabalho foram realizadas análises em Platina Universal de 4 ei$\mathrm{xos}, \mathrm{em}$ rochas protomiloniticas e miloníticas graníticas, em planos paralelos à lineação de estiramento (cortes XZ). Foram medidos, em 12 amostras, de 100 a 200 eixos-c, com uma média de 160 eixos por amostra.

\section{Discussāo dos resultados}

No milonito MG-31 (setor central da FMN) foram medidos 200 eixos-c de quartzo recristalizados ou de subgrãos de quartzo recuperados. Geralmente estes apresentam-se segregados em faixas. $O$ diagrama da Figura 4 apresenta um padrão de guirlanda cruzada do tipo I (Lister, 1977; Schmid \& Casey, 1986). Este petrotrama é caracterizado pela tendência de duas guirlandas se encon

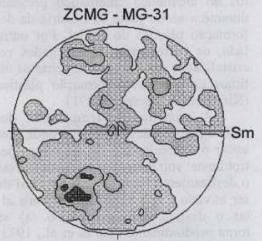

Figura 4 - Eixos-c de quartzo - amostra MG-31. Curvas de contorno espaçadas de $1.5 \%$. trarem a alguma distância do eixo intermediário Y e serem conectadas através de $Y$ por uma guirlanda simples mais ou menos ortogonal ao plano da foliação. Entretanto observa-se que a guirlanda de trend NE-SW é mais populosa que a NW-SE, e a guirlanda simples próxima a Y é oblíqua à foliação. Esta assimetria pode evidenciar uma componente rotacional (dextral) da deformação.

Este diagrama também se assemelha àqueles transicionais entre guirlanda cruzada tipo I e guirlanda de círculo minimo, sugerindo um processo intermediário entre deformação plana e achatamento (Schmid \& Casey, 1986; Fig. 5; amostra RL8330).

Este petrotrama indica várias direções de deslizamento do quartzo: os deslizamentos basais 〈a) são referentes às concentraçôes perpendiculares à foliação milonítica, os rômbicos às concentrações intermediárias e os prismáticos 〈a) referem-se às concentraçỗes ao redor do eixo-Y do elipsóide de deformação (Price, 1985; Schmid \& Casey, 1986). Observa-se portanto, nesta amostra, múltiplas direções de deslizamento, tendo favorecido a recristalização ou mesmo a formação de subgrãos de quartzo, como foi observado.

Este padrão é típico de deformação coaxial plana ou deformação intermediária entre achatamento e deformação plana. Tal hipótese é corroborada pela plotagem no Diagrama de Flinn (Passarelli, 1996; Fig. 34), no campo entre deformação plana e achatamento.

No milonito MG-32 (setor central da FMN), foram medidos 141 eixos-c de subgrâos de quartzo recuperados (Fig. 5). Apresenta um padrão cujos máximos dos eixos-c concentram-se ao longo de pequenos círculos centrados ao redor do polo da foliação, podendo porém representar já uma transição para o padrão de guirlanda cruzada do tipo I (Lister, 1977; Schmid \& Casey 1986). 


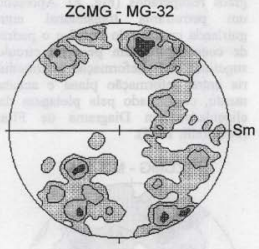

Figura 5 - Eixos-c de quartzo - amostra MG-32. Curvas de contomo espaçadas de $1.42 \%$.

Este petrotrama pode ser correlacionado a uma deformação no campo do achatamento geral (Price, 1985; Schmid \& Casey 1986). O diagrama sugere deslizamento basal 〈a〉 e rômbico dos grãos de quartzo (Price, 1985; Schmid \& Casey, 1986).

No protomilonito MG-38 (setor SW da FMN) foram medidos 140 eixosc de subgrãos de quartzo recuperados, com extinção homogênea e com tendência de contatos poligonais (Fig. 6). Mostra um padrão semelhante ao anteriormente referido, apresentando porém, uma assimetria em relação à foliação milonitica. Este padrăo pode ser interpretado como uma deformação no campo do achatamento não-coaxial, ou seja, a assimetria observada sugere uma componente rotacional na deformação, com sentido de movimento dextral.

Conforme Schmid \& Casey (1986), guirlandas de pequenos circulos são correlacionadas com valores de $\mathrm{K}<1$ (achatamento). Este sistema é indicativo de deslizamento basal e rômbico. O prisma (a) não é ativado, caracterizando um petrotrama relacionado à deformação por encurtamento axial (axisymmetric flattening), conforme

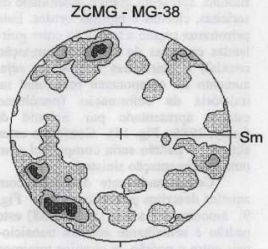

Figura 6 - Eixos-c de quartzo - amostra MG-38. Curvas de contorno de $1.43,3.57$ e $5.00 \%$.

Lister (1981) e Price (1985).

No milonito MG-114 (setor SW da FMN), foram medidos 200 eixos-c de grãos de quartzo recristalizados ou subgrãos de quartzo recuperados, normalmente em faixas segregadas (Fig. 7). Este milonito, já com fortes feiçőes de

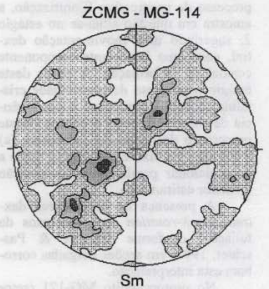

Figura 7 - Eixos-c de quartzo - amostra MG-114. Curvas de contorno de $1.2,3.5$ e $4.5 \%$. 
filonito, apresenta grande quantidade de sericitas, cloritas c biotitas verdes. Este petrotrama sugere a transição entre guirlandas cruzadas do tipo I (deformação coaxial) e guirlandas únicas, ou seja, aumento da componente rotacional na trajetória da deformação (penúltimo estágio apresentado por Schmid \& Casey, 1986; Fig. 14). Conforme estes autores, o padrão seria compativel com uma movimentação sinistral.

Comparando este diagrama com aqueles descritos por Price (1985; Fig. 9; amostras 27 a 29, 35, 37 e 38) este padrão é semelhante àqueles transicionais entre o padrão de círculos mínimos e guirlandas cruzadas do tipo I, posicionando-se no campo do achatamento geral. Conforme este autor, a variação no desenvolvimento da guirlanda parcial através de $\mathrm{Y}$ está relacionada à magnitude da componente da deformação plana relativa à componente do axisymmetric flattening da deformaçăo.

Entretanto, comparando-se com diagramas elaborados por Hippertt (1994) onde ilustra a orientação preferencial dos eixos-c de quartzo durante o processo de progressiva filonitização, a amostra em questão situa-se no estágio 2 , sugerindo uma movimentação dextral, com uma importante componente coaxial na deformação. A partir deste estágio o processo de plasticidade cristalina começa a diminuir e a transferência de solução começa a crescer. Neste processo o deslizamento prismático $\langle a\rangle$ é ativado, e o eixo-c de quartzo tende a sc posicionar paralelamente à posição de maior estiramento.

A presença de indicadores dextrais (back-rotation em segmentos da foliação, conforme Hanmer \& Passchier, 1991) em seçōes delgadas corrobora esta interpretaçāo.

No protomilonito MG-171 (setor SW da FMN) foram medidos 160 polos de eixos-c de subdomínios de gràos de quartzo com extinção ondulante e sub- grãos recuperados (Fig. 8). Apresenta um petrotrama transicional entre guirlanda cruzada do tipo I e o padrão de concentração em pequeno círculo, sugerindo uma deformação intermediária entre deformação plana e achatamento, confirmado pela plotagem das elipsidades em Diagrama de Flinn (Passarelli, 1996).

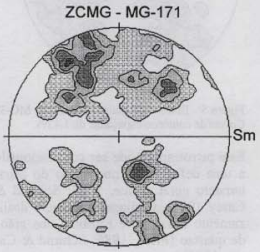

Figura 8 - Eixos-c de quartzo - amostra MG-171 Curvas de contorno espaçadas de $1.25 \%$.

Adotando-se os critérios de Lister (1981) e Price (1985, Fig. 12, amostras 43 a 45), este petrotrama é característico de guirlanda cruzada do tipo I, típico de deformação plana. Segundo Price (1985), é relacionado a baixas taxas de deformação. Nota-se a ausência de deslizamento prismático (a), ocorrendo apenas o basal (a) (Lister, 1981).

O diagrama posiciona-se onde se dá o início do aumento da componente rotacional da deformação com um movimento sinistral, confirmado pelos indicadores cinemáticos observados em afloramento.

No protomilonito MG-172 (setor NE da FMS) foram medidos 100 eixosc de subdominios de quartzo com extinção ondulante (Fig. 9). Apresenta um petrotrama pouco caracterizado, po- 


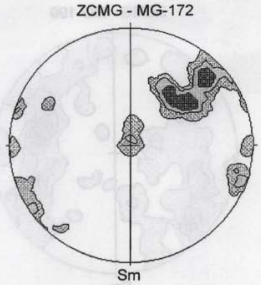

Figura 9 - Eixos-c de quartzo - amostra MG172. Curvas de contorno espacadas de $2 \%$.

dendo representar uma transição entre concentração em pequenos círculos e guirlanda cruzada do tipo I. Apresenta principalmente deslizamento basal e prismático $(\mathrm{a}\rangle$.

Este petrotrama mostra semelhanças com aqueles intermediários entre pequenos círculos e guirlanda cruzada do tipo I, apresentados por Price (1985; Fig. 9; amostra 32), resultante de deformação no campo do achatamento geral. Apresenta também semelhanças com diagramas apresentados por Lister (1981) característicos de encurtamento axial, mas com importante componente rotacional associada.

A assimetria dos polos de eixo-c, sugere uma componente rotacional da deformação de caráter sinistral. Entretanto, indicadores dextrais e sinistrais são observados no afloramento e em lâmina delgada.

No milonito MG-186 (setor central da FMN), foram medidos eixos-c de subdomínios de grãos de quartzo com extinçâo ondulante e subgrãos recuperados, apresentando um petrotrama tipico de pequenos círculos (Fig. 10). A-

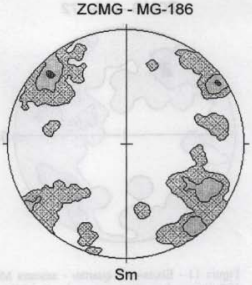

Figura 10 - Eixos-c de quartzo - amostra MG186. Curvas de contorno espaçadas de $1.88 \%$.

presenta simetria monoclínica, controlada pela distribuição dos máximos dos polos de eixos-c de quartzo ao longo de dois círculos mínimos em torno do eixo-Z e simétricos em relação à foliação milonítica. Corresponde a valores de $\mathrm{K}<1$ (campo do achatamento) conforme Passarelli (1996). Este é um caso bastante ilustrativo de cisalhamento puro, onde os planos de slip basais formam um ângulo aproximado de $90^{\circ}$ entre si e se posicionam a $45^{\circ}$ da foliação milonitica.

Conforme Lister (1981) e Price (1985; Fig. 6; amostra 7), este diagrama apresenta semelhança com petrotramas do campo do axisymmetric flattening, com deslizamento principal basal (a).

No milonito granítico MG-198 (setor central da FMN), foram medidos 160 eixos-c de subdomínios de grãos de quartzo com extinção ondulante e subgrãos recuperados (Fig. 11). Esta amostra apresenta padrão semelhante ao da amostra MG-186, mas já descaracterizado, pois seus contornos não se apresentam simétricos em relação à foliação milonítica. Sugerem-se deslizamentos 


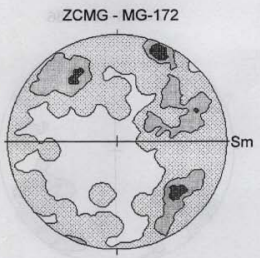

Figura 11 - Eixos-c de quartzo - amostra MG198. Curvas de contorno espaçadas de $1.88 \%$.

basal e rômbico.

Em seção delgada, a amostra apresenta porfiroclastos simétricos e evidências sugestivas de movimentação dextral (cominuição de porfiroclastos de feldspatos com caudas assimétricas).

$\mathrm{Na}$ amostra MG-199 (setor central da $F M N$ ) foram medidos 180 eixos-c de subgrãos recristalizados, com extinção homogênea, em faixas segregadas (Fig. 12). O padrão apresentado é semelhante ao da amostra MG-186 (Fig. 10). Ambos os casos são típicos de deformação coaxial em campo de achatamento ou de uma compressã̃o axial (Tullis, 1977; Lister, 1981; Dell'Angelo \& Tullis, 1989; Schmidt \& Casey 1986; Tommasi et al., 1994). São sugeridos deslizamentos romboédricos e basais.

As amostras MG-162 e MG-304 são de sienogranitos deformados, não apresentando uma orientação preferencial bem definida. Situam-se fora das faixas miloniticas. A amostra MG-162 representa um sienogranito com feições cataclásticas e dúcteis. Foram medidos 120 eixos-c de porfiroclastos de quartzo, com forte extinção ondulante, em vários domínios de cada grão (Fig. 13). $\mathrm{O}$ diagrama sugere deslizamento princi-

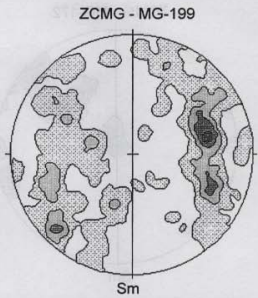

Figura 12 - Eixos-c de quartzo - amostra MG199. Curvas de contorno espaçadas de $1.67 \%$.

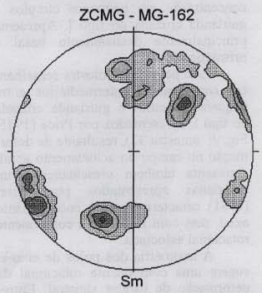

Figura 13 - Eixos-c de quartzo - amostra MG162. Curvas de contomo espaçadas de $2.5 \%$.

pal basal (a).

$\mathrm{Na}$ amostra MG-304 foram medidos 140 eixos-c de quartzo com extinção ondulante, em subdomínios de cada grảo (Fig. 14). Este diagrama mostra um 


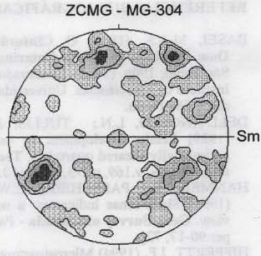

Figura 14- Eixos-c de quartzo - amostra MG304. Curvas de contomo espaçadas de $1.42 \%$.

padrão muito semelhante aos apresentados por Sakakibara et al. (1992, Figs. 5c e 7). Os autores correlacionam este petrotrama com guirlandas cruzadas do tipo I (Lister, 1977), embora apresente grande dispersão nas concentrações dos eixos-c.

Este petrotrama é relacionado a uma deformaçâo plana, com deslizamento basal e prismático 〈a〉 (Lister, 1981).

\section{CONCLUSŌES}

A evolução cinemática desta zona de cisalhamento foi definida com base em estruturas mesoscópicas e análises microestruturais que abrangeram o Método de Fry e análises dos petrotramas de eixos-c de quartzo (Passarelli, 1996).

Os resultados obtidos pela análise dos petrotramas de quartzo mostram-se coerentes com as estruturas mesoscópicas (indicadores cinemáticos dextrais e sinistrais, porfiroclastos simétricos), microscópicas (porfiroclastos simétricos, por vezes com sombras de pressão simétricas), análises pelo Método de Fry e plotagem em Diagrama de Flinn, apresentados e discutidos em Passarelli
(1996)

Estas análises mostram que uma importante componente da deformação estava associada a cisalhamento puro, podendo ter acarretado movimentações sinistrais em inflexões locais da foliação milonítica.

Os petrotramas mostram claramente o predomínio da deformação coaxial no setor central da ZCMG, preferencialmente no campo do achatamento e, nos demais setores da ZCMG, a componente não-coaxial da deformação é mais acentuada, também no campo do achatamento. Os deslizamentos intracristalinos, predominantemente basais, sugerem temperaturas relativamente baixas quando do desenvolvimento destas rochas miloníticas (Mainprice \& $\mathrm{Ni}$ colas, 1989).

Nas amostras cujas curvas de contorno dos polos de eixo-c tendem a uma simetria em relação a foliação milonítica, mas com densidades não simétricas, a indicativa é de uma deformação não coaxial superposta a uma deformação coaxial (conforme simulaçōes citadas em Lee et al., 1987). No entanto, como observado por Kirchner \& Teyssier (1991), o petrotrama de agregados cristalinos pode gravar apenas os últimos estágios da deformação plástica. Este fato pode sugerir que os dois processos (deformação coaxial e não-coaxial) atuaram conjuntamente na ZCMG, pela análise dos petrotramas obtidos a partir de grãos de quartzo com extinçāo ondulante e recristalizados com extinção homogênea.

$\mathrm{O}$ ângulo de abertura da guirlanda de círculo mínimo foi correlacionado com mudanças na taxa de deformação e temperaturas para petrotramas produzidos experimentalmente por Tullis (1977). O ângulo de abertura aumenta continuamente com o aumento da temperatura ou com o decréscimo da taxa de deformação (Tullis, 1977; Schmid \& Casey, 1986). A partir destas observa- 
çôes, as amostras MG-31, 38, 171, 186 e 199 estariam correlacionadas a baixas temperaturas ou taxas de deformação elevadas.

A partiçâo da deformação (conforme definida por Ramsay \& Huber, 1983), a orientação original dos clastos e o movimento relativo entre a matriz e o objeto rígido, também podem explicar a presença de indicadores cinemáticos opostos cogenéticos.

A deformação no estado sólido deu-se principalmente sob baixas temperaturas (fácies xisto-verde), evidenciada principalmente pela mineralogia das rochas miloníticas, pela presença de filonitos, bem como pelo predomínio de deslizamento basal dos grãos de quartzo. Entretanto, algumas evidências sugerem envolvimento de temperaturas moderadas para a geração das rochas miloníticas, devido à presença de fraturamentos $\mathrm{em}$ plagioclásio e presença de deslizamentos prismático 〈a) e basal do quartzo.

Apesar das rochas da ZCMG apresentarem uma orientação cristalográfica desenvolvida em temperaturas relativamente baixas, esta originou-se sob condições de alta taxa de deformaçåo, evidenciada por minerais deformados e estirados e pela frequiente paralelização das superficies $\mathrm{S}$ e C. A mineralogia observada e as altas taxas de deformação obtidas podem explicar as características dúcteis da ZCMG associadas a baixas temperaturas. A presença de água no sistema, favorecendo o processo de cristalização de minerais micáceos, que atuam como verdadeiros lubrificantes, pode contribuir no aumento das condições de ductilidade.

A atuação de um achatamento muito importante, caracterizado pelos elipsóides de deformação oblatos, associado a uma significativa componente de deformação coaxial, pode caracterizar o caráter transpressivo desta zona de cisalhamento.

\section{REFERÊNCIAS BIBLIOGRÁFICAS}

\section{BASEI, M.A.S. (1985) O Cinturão} Dom Feliciano em Santa Catarina. São Paulo, 190p. (Tese - Doutorado) Instituto de Geociências, Universidade de São Paulo.

DELL'ANGELO, L.N.; TULLIS, J. (1989) Fabric development in experimentally sheared quartzites. Tectonophysics, v.169, n.1-3, p.97-110.

HANMER, S.; PASSCHIER, C.W. (1991) Shear-sense indicators: a review. Geol. Survey of Canada - Paper $90-17,72 \mathrm{p}$.

HIPPERTT, J.F. (1994) Microstructures and c-axis fabrics indicative of quartz dissolution in sheared quartzites and phyllonites. Tectonophysics, v. 229 , p.141-163.

KIRSCHNER, D.; TEYSSIER, C. (1991) Quartz c-axis fabric differences between porphyroclasts and recrystallized grains. Journal of Structural Geology, v.13, n.1, p.105-109.

LEE, J; MILLER, E.L; SUTTER, J.F. (1987) Ductile strain and Metamorphism in a Extensional Tectonic Setting: a case study from the northern Snake Range, Nevada, USA. In: COWARD, M.P.; DEWEY, J.F.; HANCOCK. P.L. (eds.). Continental Extensional Tectonics. Oxford, Geological Society by Blackwell, p.267-298. (Geological Society, Special Publication, n.28).

LISTER, G.S. (1977) Discussion: crossed-girdle c-axis fabrics in quartzites plastically deformed by plane strain and progressive simple shear. Tectonophysics, v.39, n.1-3, p.51-54.

LISTER, G.S. (1981) The effect of the basal-prism mechanism switch on fabric development during plastic deformation of quartzite. Journal of Structural Geology, v.3, n.1, p.6775. 
LLOYD, G.E.; LAW, R.D.; MAINPRICE, D.; WHEELER, J. (1992) Microstructural and crystal fabric evolution during shear zone formation. Journal of Structural Geology, v. 14, n. $8-9$, p. 1079-1100.

MAINPRICE, D.; NICOLAS, A. (1989) Development of shape and lattice preferred orientations: application to the seismic anisotropy of the lower crust. Journal of Structural Geology, v.11, n.1-2, p.175-189.

PASSARELLI, C.R. (1996) Análise estrutural e caracterização do magmatismo da Zona de Cisalhamento Major Gercino, SC. São Paulo, 179p. (Dissertação - Mestrado) - Instituto de Geociências, Universidade de São Paulo.

PRICE, G.P. (1985) Preferred orientations in quartzites. In: WENK, H.R. (ed.). Preferred Orientation in Deformed Metals ans Rocks: an Introduction to Modern Texture Analysis. Orlando, Academic Press. p. 385-406.
RAMSAY, J.G.; HUBER, M.I. (1983) The techniques of modern structural geology. London, Academic Press. v. $1,307 \mathrm{p}$.

SAKAKIBARA, N.; HARA, I.; KANAI, K.; KAIKIRI, K.; SHIOTA, T.; HIDE, K.; PAULITSCH, P. (1992) Quartz microtextures of the Sambagawa schists and their implications in convergent margin processes. The Island Arc, v.1, p.186-197.

SCHMID, S.M.; CASEY, M. (1986) Complete fabric analysis of some commonly observed quartz c-axis patterns. In: HOBBS, B.E.; HEARD, H.C. (eds.). Mineral and rock deformation; laboratories studies; the Paterson volume. Washington, American Geophysical Union. p.263286. (Geophysical Monograph, n.36).

TULLIS, J.; CHRISTIE, J.M.; GRIGGS, D.T. (1973) Microstructures and preferred orientations of experimentally deformed quartzites. Bulletin Geological Society of American, v.84, n.1, p.297-314.

C.R.Passarelli - Instituto de Geociências, Universidade de São Paulo, Caixa Postal 11.348, CEP 05422-970, São Paulo, SP, Brasil. 